\title{
Clinical Heterogeneity in two patients with Noonan-like Syndrome associated with the same SHOC2 mutation
}

\author{
Donatella Capalbo, Maria Giuseppa Scala, Daniela Melis, Giorgia Minopoli, Nicola Improda, Loredana Palamaro, \\ Claudio Pignata and Mariacarolina Salerno
}

\begin{abstract}
Noonan-like syndrome with loose anagen hair (NS/LAH; OMIM \#607721) has been recently related to the invariant c. $4 \mathrm{~A}>\mathrm{G}$ missense change in SHOC2. It is characterized by features reminiscent of Noonan syndrome. Ectodermal involvement, short stature associated to growth hormone (GH) deficiency (GHD), and cognitive deficits are common features. We compare in two patients with molecularly confirmed NS/LAH diagnosis, the clinical phenotype and pathogenetic mechanism underlying short stature. In particular, while both the patients exhibited a severe short stature, GH/IGFI axis functional evaluation revealed a different pathogenetic alteration, suggesting in one patient an upstream alteration (typical GHD) and in the other one a peripheral GH insensitivity. Since only a few cases of NS/LAH associated to SHOC2 mutations have been so far described, the complex phenotype of the syndrome and the exact mechanism impairing GH/IGFI axis still remain to be elucidated and studies on larger cohort of subjects are needed to better delineate this syndrome.
\end{abstract}

Keywords: Noonan-like Syndrome with loose anagen hair, Growth hormone deficiency, Growth hormone insensitivity

\section{Background}

"Noonan-like syndrome with loose anagen hair" (NS/ LAH OMIM60772) is a syndrome first described in 2003, characterized by features reminiscent of NS and a unique pattern of ectodermal abnormalities [1]. Recently, Cordeddu et al. discovered that an invariant mutation in SHOC2, c.4A $>$ G, predicting the p.Ser2Gly change in the encoded protein, underlies this condition. SHOC2 encodes a scaffold protein that positively modulates RAS-MAPK signal flow. The mutation was documented to promote $\mathrm{N}$-myristoylation of the protein, and to drive aberrant targeting of $\mathrm{SHOC} 2$ to the plasma membrane and increased ERK activation in a cell context-specific fashion [2]. The phenotype of these subjects is characterized by facial features reminiscent of NS, short stature, cognitive deficits, distinctive hyperactive behavior, congenital hearth disease, and easily pluckable, sparse, thin, slow-growing hair in the anagen phase but lacking an inner and outer root sheaths.

* Correspondence: salerno@unina.it

Department of Pediatrics, "Federico II" University of Naples, Naples, Italy
Short stature is one of the most common features observed in NS as well as in other disorders associated to RAS-MAPK dysregulation. It is well known that the RAS-MAPK transduction pathway plays a key role in growth hormone $(\mathrm{GH})$ signaling [3]. However, the exact mechanism of impaired GH-IGF1-axis in patients with aberrant RAS-MAPK signaling is still controversial. An altered response of $\mathrm{GH}$ to stimulation tests has been reported in some children $[4,5]$, whereas other authors have reported normal GH secretion with low IGF1 levels suggesting a peripheral GH insensitivity (GHI) [6,7]. GHI is a condition characterized by the peripheral resistance to GH action [8-10]. Transduction of the signals elicited by GHR is mediated by the JAK/STAT pathway. Tyrosine phosphorylation of JAK2 and STAT5 plays a crucial role in such a process, which eventually results in gene transcription [11-13]. The most common form of GHI is due to GHR mutations; other forms are caused by abnormalities in the signaling cascade downstream to GHR and, in particular, involving STAT5b $[9,11]$. In subjects with STAT5b defects short stature is associated 
with immunodeficiency and severe pulmonary involvement $[8,14,15]$.

In children with NS/LAH short stature is mainly associated to proven GH deficiency (GHD) [2].

So far, only a few patients with NS/LAH have been described and the phenotype of the syndrome still remains to be delineated. We recently reported on a patient affected with this syndrome, who exhibited a GHI [16]. Herein, we compare the clinical phenotype and the pathogenetic mechanism underlying short stature and abnormal GH/IGFI axis between the already described patient and a further affected child with the same mutation of the SHOC2 gene.

\section{Subjects}

\section{Patient 1}

The patient was born preterm (34 weeks of gestation) with a pregnancy complicated by polyhydramnios. Parents were not consanguineous. Birth weight was $2.450 \mathrm{~kg}$ ( $75^{\text {th }}$ centile), length was $45 \mathrm{~cm}\left(25^{\text {th }}-50^{\text {th }}\right.$ centile). She was referred to our attention at the age of 7 years for short stature. Physical examination revealed macrocephaly, high forehead, epicanthic folds, palpebral ptosis, hyperthelorism, high and narrow palate, pterigium colli, pectus excavatum with widely spaced nipples, deep palmar and plantar creases (Figure 1a). She had severe growth delay: weight was $13 \mathrm{~kg}(-4.4 \mathrm{SDS})$ and height was $97 \mathrm{~cm}(-5.7 \mathrm{SDS})$, with impaired linear growth velocity ( $3 \mathrm{~cm} /$ year). Bone age was delayed by three years. Karyotype was normal (46, XX). Neurological evaluation revealed a mild psychomotor delay (IQ: 52) with impairment of verbal and language abilities. Cerebral MRI showed hypoplastic corpus callosum. Based on these features, NS disease genes were screened (PTPN11, KRAS, SOS1, MEK1, BRAF) but mutation analysis failed to reveal any causative mutation.

Biochemical evaluation of GH-IGF1 axis, performed to investigate the cause underlying short stature, revealed low serum levels of IGF1 (27 ng/ml, nv 60-350) and normal GH peak after arginine stimulation $(16 \mathrm{ng} / \mathrm{ml})$, thus excluding a GHD [17] and suggesting a condition of mild GH insensitivity (GHI). An IGFI generation test confirmed the condition of GHI, revealing only a mild increase of IGFI levels $(55 \mathrm{ng} / \mathrm{ml})$ after stimulation with exogenous $\mathrm{GH}$ with respect to basal values $(30 \mathrm{ng} / \mathrm{ml})$. Moreover, the peak value obtained was still below the mean value for age $(60-350 \mathrm{ng} / \mathrm{ml})$. GHI was not related to mutations in $\mathrm{GH}$ receptor in that molecular analysis of GHR gene was normal. Moreover, intracellular signalling elicited by GHR perturbation, evaluated through the analysis of GH-induced tyrosine phosphorylation of Signal Transducers and Activators of Transcription (STAT)5, was normal.

The patient underwent a therapeutic trial with recombinant human (rh) GH at a mean dose of $45 \mu \mathrm{g} / \mathrm{kg} / \mathrm{die}$. However, no significant improvement in linear growth was observed. Nevertheless, an arrest of growth velocity was observed when GH treatment was stopped. Thus, $\mathrm{GH}$ was re-started in order to normalize growth velocity (Figure 2a).

Over time, several ectodermal abnormalities became evident, including nail dystrophy, dry, fine textured, sparse hair, which were easily pulled from the scalp, and dry, hairless, darkly pigmented skin. Such a distinctive association prompted SHOC2 mutation analysis which confirmed the presence of the disease-causing mutation (c.4A > G, p.Ser2Gly), thus confirming diagnosis of NS/ LAH. At 9 years, she suddenly presented with complex motor and vocal tics characterized by repetitive stereotyped movements predominantly involving facial and shoulder muscles and repetitive sounds, which persisted for more than 1 year. Major causes of secondary tics disorders in childhood were excluded, including occurrence of neurodegenerative disease, central nervous system infections, pediatric autoimmune neuropsychiatric disorder associated with streptococcal infection (PANDAS)

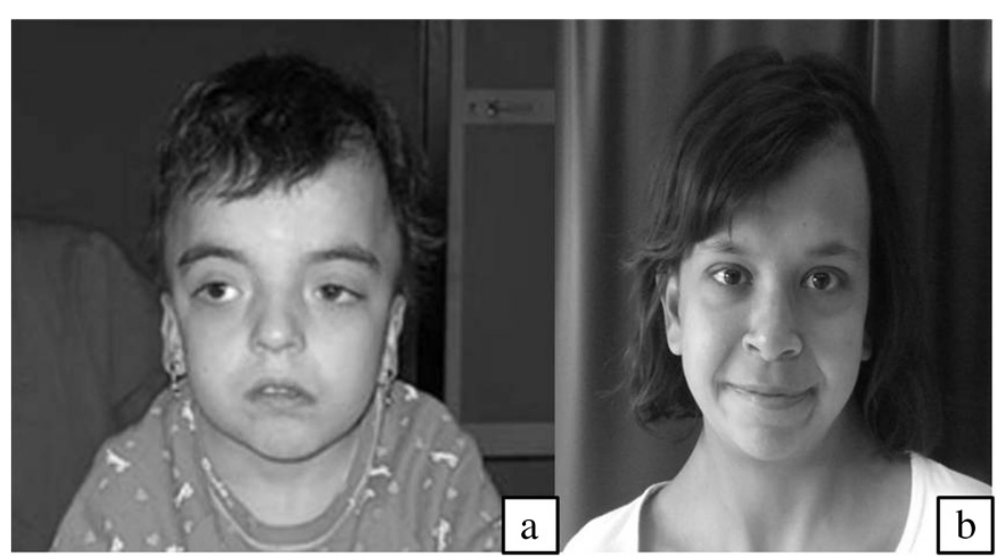

Figure 1 Patient 1 at 9 years of age (a) and patient 2 at 13 years (b) in a frontal view. 


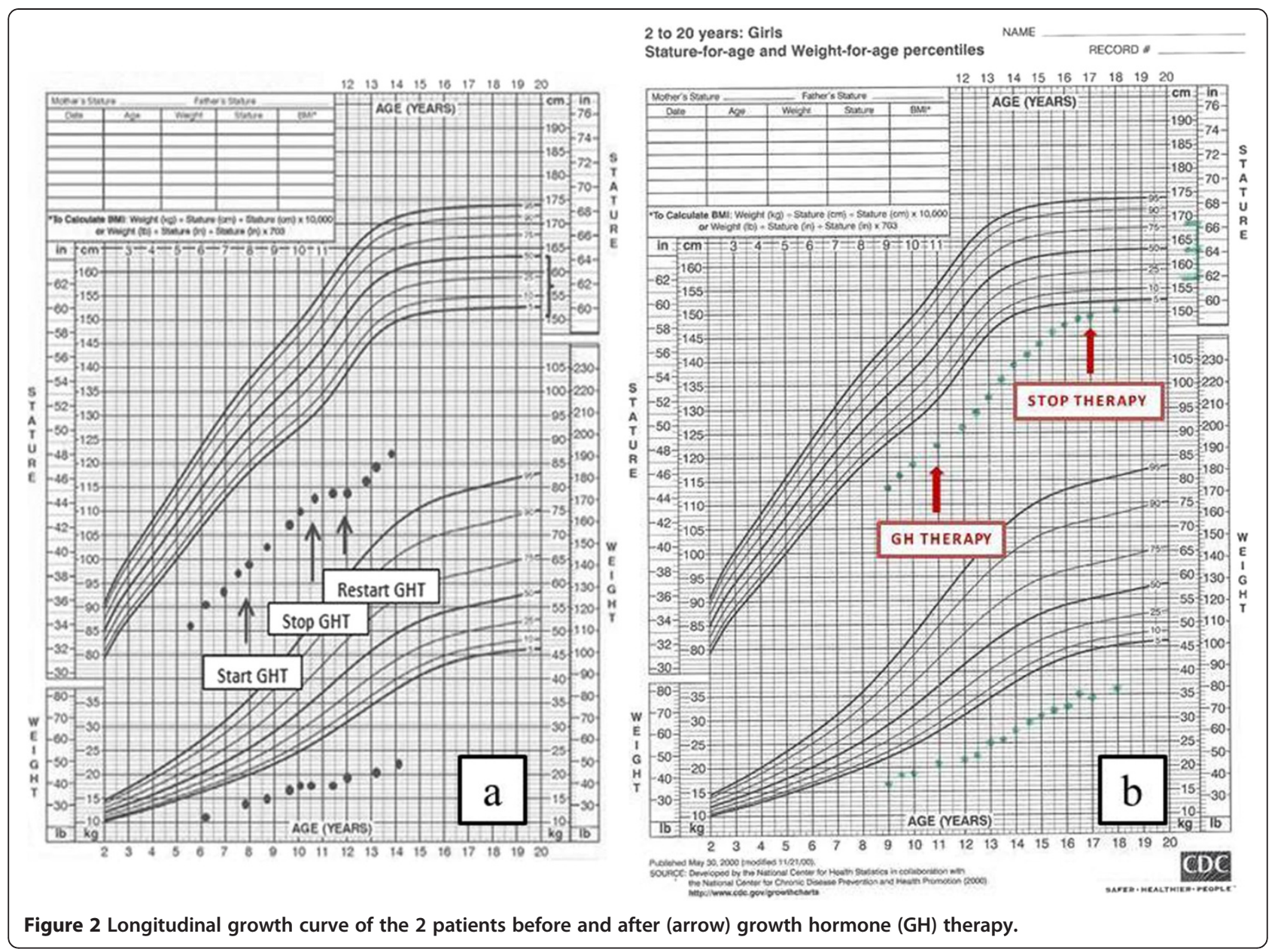

or drug-related effects [18]. A few months later, she presented with a generalized convulsive event. Electroencephalography revealed the presence of focal abnormalities in both parietal and occipital areas, whereas MRI confirmed the previous finding of corpus callosum hypoplasia and showed diffuse reduction in the white matter. She was then treated with carbamazepine with a good control on seizures but without any effect on tic disorders. She is now 13 years old. Despite a 6-years GH treatment, she still has a severe short stature (height -5 SDS) (Figure 2a), and IGF1 levels well below the normal range $(93.5 \mathrm{ng} / \mathrm{ml}$; nv 180-780) [16].

\section{Patient 2}

The patient was born at term (40 weeks of gestation) after a normal pregnancy and caesarian delivery from not consanguineous parents. Birth weight was $3.75 \mathrm{~kg}$ (50-75 ${ }^{\text {th }}$ centile), length was $48 \mathrm{~cm}\left(10-25^{\text {th }}\right.$ centile) and head circumference $37 \mathrm{~cm}\left(>90^{\circ}\right)$. At birth, a large atrial septal defect with pulmonary hyperflow was detected.

She was referred to our Department at the age of 9 years because of short stature. Physical examination revealed macrocephaly, high forehead, epicanthic folds, low-set and posterior angulated left ear, hyperthelorism, short neck with redundant skin, pectus excavatum, fine, dry, fine textured, sparse hair, darkly pigmented skin with cafe au lait spots, tuberous angioma in the left hypochondrium, hyperextensible joints and mild scoliosis (Figure $1 \mathrm{~b})$. She had a severe growth delay: weight was $16.5 \mathrm{~kg}(-3.72 \mathrm{SDS})$ and height was $113.5 \mathrm{~cm}(-3.21$ SDS). Bone age was delayed by two years. Karyotype was normal $(46, \mathrm{XX})$. She had only a mild psychomotor delay (IQ 65) and behavioral problems. Cerebral MRI showed type I Chiari malformation.

The biochemical evaluation showed a subclinical hypothyroidism $(\mathrm{SH})$ on the basis of a mild increase of TSH levels in the absence of thyroid autoantibodies which normalized over time, associated with normal values of circulating hormones, thus not requiring replacement therapy [19-22]. The presence of APA was also excluded as an autoimmune cause of short stature [23]. Biochemical evaluation of GH-IGF1 axis, performed to investigate the cause of the short stature, revealed abnormal GH peak after clonidine stimulation 
(9 $\mathrm{ng} / \mathrm{ml})$ and arginine stimulation (5.3 $\mathrm{ng} / \mathrm{dL}$ ) with serum levels of IGF1 at the lower limit of normal range (70.4 $\mathrm{ng} / \mathrm{ml}$ ), indicative of a condition of partial GH deficiency She was then started on recombinant human (rh) $\mathrm{GH}$ at a mean dose of $40 \mu \mathrm{g} / \mathrm{kg} / \mathrm{die}$, with only a blunted response to treatment (Figure $2 b$ ). At the age of 17 years she stopped the therapy (Figure 2b).

Later on during the follow-up, the girl showed an improvement in her psychomotor development and behavior skills.

Since at the age of 14 years no signs of pubertal development were evident, a LHRH test was performed revealing normal activation of the gonadotropic axis (peak

Table 1 Phenotipic features of Noonan-like syndrome with loose anagen hair in our two patients

\begin{tabular}{|c|c|c|}
\hline & Patient 1 & Patient 2 \\
\hline \multicolumn{3}{|l|}{ Skin and hair } \\
\hline Dark skin & + & + \\
\hline Hyperkeratosis & - & - \\
\hline Dermatitis/eczema & - & - \\
\hline Sparse/absent scalp hair & + & + \\
\hline Curly hair & - & - \\
\hline Loose anagen hair & + & + \\
\hline \multicolumn{3}{|l|}{ Head and neck } \\
\hline Macrocephaly & + & + \\
\hline \multicolumn{3}{|l|}{ Eyes } \\
\hline Ptosis & - & + \\
\hline Epicanthal folds & + & + \\
\hline \multicolumn{3}{|l|}{ Nose } \\
\hline Depressed nasal bridge & - & - \\
\hline Anteverted nostrils & - & - \\
\hline \multicolumn{3}{|l|}{ Oral cavity } \\
\hline High-arched palate & - & + \\
\hline \multicolumn{3}{|l|}{ Ears } \\
\hline Apparently low-set ears & + & - \\
\hline Retroverted ears Neck & + & - \\
\hline \multicolumn{3}{|l|}{ Neck } \\
\hline Broad, short, webbed & + & + \\
\hline \multicolumn{3}{|l|}{ Chest } \\
\hline Pectus excavatum & + & + \\
\hline \multicolumn{3}{|l|}{ Cardiovascular } \\
\hline VSD/ASD/PDA & + & - \\
\hline \multicolumn{3}{|l|}{ Cerebral abnormalities } \\
\hline Dilated ventricles & - & - \\
\hline Mental retardation & - & + \\
\hline Tic & - & + \\
\hline \multicolumn{3}{|l|}{ Growth and development } \\
\hline Short stature & + & + \\
\hline Lymphatic dysplasias & + & - \\
\hline
\end{tabular}

of LH $14.4 \mathrm{mU} / \mathrm{mL}$; peak of FSH $21.7 \mathrm{mU} / \mathrm{mL}$ ). Nevertheless, no pubertal progression was observed in the following years and at the age of 16 years she was started on hormonal replacement.

The complex clinical phenotype prompted to the clinical diagnosis of NS/LAH and molecular analysis of SHOC2 revealed the presence of the disease-causing mutation (c.4A > G, p.Ser2Gly).

In Table 1 a comparison of the two phenotypes has been reported.

\section{Discussion}

We reported on two patients with molecularly confirmed diagnosis of NS/LAH exhibiting different features of the disease and different pathogenetic mechanisms underlying the impairment of GH-IGFI axis resulting in short stature.

Both patients had the similar facial dysmorphism, skeletal abnormalities, ectodermal abnormalities and psychomotor delay, even though these features were more pronounced in the patient 1 . Patient 1 also had epilepsy and atypical neurologic signs such as chronic vocal and motor tics, never previously reported in patients with $\mathrm{SHOC2}$ mutations or in any other condition due to RAS-MAPK dysregulation. The precise etiology of chronic tics in childhood often remains elusive. However, abnormalities in the dopamine pathways have been supposed as possible mechanism underlying neurotransmitter alterations [24]. Recent evidence suggests that RAS-MAPK pathway is involved in signal transduction that follows dopamine receptors triggering [25]. Thus, one could speculate that in our patient dysregulation of RAS-MAPK due to dysregulated SHOC2 function might be related to tics disorders through an alteration of dopamine-signaling. In keeping with this, studies on Gilles de la Tourette syndrome (GTS), one of the most frequent causes of chronic tics in infancy, also indicate a potential role of immune activation, mediated by RAS-MAPK stimulating cytokines, in the pathogenesis of tics and other hyperkinetic disorders [26].

As for developmental and behavioral features, again patient 1exhibited persistent alterations during adolescence, differently from patient 2 who only had a mild delay improving over time.

Both patients had severe short stature, even though GH/IGFI axis was differently altered. In fact, in the patient 1 the evaluation of GH-IGFI axis revealed a condition of GHI, whereas in patient 2 a partial GH deficiency was found. So far, GHD represents the most common cause of short stature in NS/LAH syndrome. Differently, GHI has never been described in NS/LAH subjects. In our second patient, molecular analysis of GHR and GH-induced phosphorylation of STAT5 were normal, thus excluding the most common receptorial or 
postreceprtorial causes of peripheral insensitivity to $\mathrm{GH}$. Since both patients with GHD and with GHI share the same mutation, it seems unlikely that this mutation cause GHI per se. However, it is conceivable that SHOC2 mutation alters GHR signaling through dysregulation of RAS-MAPK pathway, thus contributing to cause GHI. In keeping with this, $\mathrm{GH}$ replacement therapy was unsuccessful in the patient 1 . The observation that also in the patient 2, in spite of GHD the GH replacement therapy was not fully successful indicates that $\mathrm{SHOC2}$ has multiple roles in either central or peripheral control of GH-IGFI axis functionality.

The clinical heterogeneity in our 2 patients carrying the same mutation, is not surprising as other monogenic diseases have been already shown to have a different phenotype despite the same causing mutation [27-30]. For most of these conditions, molecular basis of this heterogeneity are not well delineated. Disease modifying genes, variation in environmental exposures, as well as system dynamics may come into play in modulating clinical expression of the disease [31].

\section{Conclusion}

In conclusion, we reported on two patients with $\mathrm{NS} / \mathrm{LAH}$ due to the invariant c.4A $>\mathrm{G}$ mutation in $S H O C 2$, with a different phenotype of the disease and severe short stature related to different mechanisms impairing GH-IGFI axis. Since only a few cases of the NS/LAH have so far been described, studies on larger cohort of subjects are needed to better delineate the phenotypic heterogeneity and to better define the pathogenetic mechanism underlying short stature in these patients.

\section{Consent}

Written informed consent was obtained from the parents of the patients for publication of this Case report and any accompanying images. A copy of the written consent is available for review by the Editor-in-Chief of this journal.

\section{Competing interests}

The authors declare that they have no competing interests.

\section{Authors' contributions}

All authors have equally participated in drafting of the manuscript and/or critical revision of the manuscript for important intellectual content. All authors read and approved the final manuscript.

Received: 13 September 2012 Accepted: 18 September 2012 Published: 20 September 2012

\section{References}

1. Mazzanti L, Cacciari E, Cicognani A, Bergamaschi R, Scarano E, Forabosco A: Noonan-like syndrome with loose anagen hair: a new syndrome? Am J Med Genet 2003, 118A:279-286.

2. Coreddu V, Di Schiavi E, Pennacchio LA, Ma'ayan A, Sarkozy A, Fodale V, Cecchetti S, Cardinale A, Martin J, Schackwitz W, Lipzen A, Zampino G, Mazzanti L, Diglio MC, Martinelli S, Flex E, Lepri F, Bartholdi D, Kutsche K, Ferrero GB, Anichini C, Selicorni A, Rossi C, Tenconi R, Zenker M, Merlo D,
Dallapiccola B, lyengar R, Bazzicalupo P, Gelb BD, Tartarglia M: Mutation of SHOC2 promotes aberrant protein $\mathrm{N}$-myristoilation and causes Noonanlike syndrome with loose anagen hair. Nat Genet 2009, 41:1022-1026.

3. Padidela R, Camacho Hubner C, Attie KM, Savage MO: Abnormal growth in Noonan syndrome: genetic and endocrine features and optimal treatment. Horm Res 2008, 70:129-136.

4. Romano AA, Blethen SL, Dana K, Noto RA: Growth hormone treatment in Noonan syndrome: the national cooperative growth study experience. J Pediatr 1996, 128:S18-S21

5. Cotteril AM, McKenna WJ, Brady AF, Sharland M, Elsawi M, Yamada M, Camacho-Hubner C, Kelnar CJ, Dunger DB, Patton MA, Savage MO: The short term effects of growth hormone therapy on height velocity and cardiac ventricular wall thickness in children with Noonan's syndrome. J Clin Endocrinol Metab 1996, 81:2291-2297.

6. Limal JM, Parfait B, Cabrol S, Bonnet D, Leheup B, Lyonnet S, Vidaud M, Le Bouc $Y$ : Noonan syndrome: relationship between genotype, growth and growth factors. J Clin Endocrinol Metab 2006, 91:300-306.

7. Ferreira LV, Souza SA, Arnhold IJ, Mendoca BB, Jorge AA: PTPN11 (protein tyrosine phosphatase, nonreceptor type 11) mutations and response to growth hormone therapy in children with Noonan syndrome. J Clin Endocrinol Metab 2005, 90:5377-5381.

8. Rosenfeld RG, Rosenbloom AL, Guevara-Aguirre J: Growth hormone (GH) insensitivity due to primary GH receptor deficiency. Endocr Rev 1994, 15:369-390

9. Salerno M, Balestrieri B, Matrecano E, Officioso A, Rosenfeld RG, Di Maio S, Fimiani G, Ursini MV, Pignata C: Abnormal GH receptor signaling in children with idiopathic short stature. J Clin Endocrinol Metab 2001, 86:3882-3888.

10. Ursini MV, Gaetaniello L, Ambrosio R, Matrecano E, Apicella AJ, Salerno MC, Pignata C: Atypical X-linked SCID phenotype associated with growth hormone hyporesponsiveness. Clin Exp Immunol 2002, 129(3):502-509.

11. Hwa V, Nadeau K, Wit JM, Rosenfeld RG: STAT5b deficiency: lessons from STAT5b gene mutations. Best Pract Res Clin Endocrinol Metab 2011, 25:61-75.

12. Amorosi S, Russo I, Amodio G, Garbi C, Vitiello L, Palamaro L, Adriani M, Vigliano I, Pignata C: The cellular amount of the common gamma-chain influences spontaneous or induced cell proliferation. J Immunol 2009, 182(5):3304-3309.

13. Vigliano I, Palamaro L, Bianchino G, Fusco A, Vitiello L, Grieco V, Romano R, Salvatore M, Pignata C: Role of the common $y$ chain in cell cycle progression of human malignant cell lines. Int Immunol 2012, 24:159-167.

14. Montella S, Maglione M, Bruzzese D, Mollica C, Pignata C, Aloj G, Manna A, Esposito A, Mirra V, Santamaria F: Magnetic resonance imaging is an accurate and reliable method to evaluate non-cystic fibrosis paediatric lung disease. Respirology 2012, 17(1):87-91.

15. Montella S, Santamaria F, Salvatore M, Pignata C, Maglione M, lacotucci P, Mollica C: Assessment of chest high-field magnetic resonance imaging in children and young adults with noncystic fibrosis chronic lung disease: comparison to high-resolution computed tomography and correlation with pulmonary function. Invest Radiol 2009, 44(9):532-538.

16. Capalbo D, Melis D, De Martino L, Palamaro L, Riccomagno S, Bona G, Cordeddu V, Pignata C, Salerno M: Noonan-like syndrome with loose anagen hair associated with growth hormone insensitivity and atypical neurological manifestations. Am J Med Genet A 2012, 158A(4):856-860.

17. Corneli G, Di Somma C, Prodam F, Bellone J, Bellone S, Gasco V, Baldelli R, Rovere S, Schneider HJ, Gargantini L, Gastaldi R, Ghizzoni L, Valle D, Salerno M, Colao A, Bona G, Ghigo E, Maghnie M, Aimaretti G: Cut-off limits of the GH response to GHRH plus arginine test and IGF-I levels for the diagnosis of GH deficiency in late adolescents and young adults. Eur J Endocrinol 2007, 157(6):701-708.

18. Dooley JM: Tic Disorders in childhood. Semin Pediatr Neurol 2006, 13:231-242.

19. Wasniewska M, Salerno M, Cassio A, Corrias A, Aversa T, Zirilli G, Capalbo D, Bal M, Mussa A, De Luca F: Prospective evaluation of the natural course of idiopathic subclinical hypothyroidism in childhood and adolescence. Eur J Endocrinol 2009, 160(3):417-421.

20. Wasniewska M, Corrias A, Aversa T, Valenzise M, Mussa A, De Martino L, Lombardo F, De Luca F, Salerno M: Comparative evaluation of therapy with L-thyroxine versus no treatment in children with idiopathic and mild subclinical hypothyroidism. Horm Res Paediatr 2012, 77(6):376-381 
21. Cerbone M, Bravaccio C, Capalbo D, Polizzi M, Wasniewska M, Cioffi D, Improda N, Valenzise M, Bruzzese D, De Luca F, Salerno M: Linear growth and intellectual outcome in children with long-term idiopathic subclinical hypothyroidism. Eur J Endocrinol 2011, 164(4):591-597.

22. Radetti G, Maselli M, Buzi F, Corrias A, Mussa A, Cambiaso P, Salerno M, Cappa M, Baiocchi M, Gastaldi R, Minerba L, Loche S: The natural history of the normal/mild elevated TSH serum levels in children and adolescents with Hashimoto's thyroiditis and isolated hyperthyrotropinaemia: a 3-year follow-up. Clin Endocrinol (Oxf) 2012, 76(3):394-398.

23. De Bellis A, Salerno M, Conte M, Coronella C, Tirelli G, Battaglia M, Esposito V, Ruocco G, Bellastella G, Bizzarro A, Bellastella A: Antipituitary antibodies recognizing growth hormone (GH)-producing cells in children with idiopathic GH deficiency and in children with idiopathic short stature. J Clin Endocrinol Metab 2006, 91(7):2484-2489.

24. Du JC, Chiu TF, Lee KM, Wu H: Tourette Syndrome in children: an update review. Pediatr Neonatol 2010, 51:255-264.

25. Zhen X, Zhang J, Jhonson GP, Friedman E: D4 dopamine receptor differentially regulates Akt/Nuclear factor-Kb and extracellular signalregulated kinase pathways in D4MN9D cells. Mol Pharmacol 2010, 60:857-864.

26. Martino D, Dale RC, Gilbert DL, Giovannoni G, Leckman JF: Immunopathogentic mechanisms in Tourette syndrome: a critical review. Mov Disord 2009, 24:1267-1279.

27. Capalbo D, Fusco A, Aloj G, Improda N, Vitiello L, Dianzani U, Betterle C, Salerno M, Pignata C: High intrafamilial variability in autoimmune polyendocrinopathy-candidiasis-ectodermal dystrophy: a case study. $J$ Endocrinol Invest 2012, 35(1):77-81.

28. Capalbo D, Mazza C, Giordano R, Improda N, Arvat E, Cervato S, Morlin L, Pignata C, Betterle C, Salerno M: Molecular background and genotypephenotype correlation in autoimmune-polyendocrinopathy-candidiasisectodermal-distrophy patients from Campania and in their relatives. J Endocrinol Invest 2012, 35(2):169-173.

29. Mazza C, Buzi F, Ortolani F, Vitali A, Notarangelo LD, Weber G, Bacchetta R, Soresina A, Lougaris V, Greggio NA, Taddio A, Pasic S, de Vroede M, Pac M, Kilic SS, Ozden S, Rusconi R, Martino S, Capalbo D, Salerno M, Pignata C, Radetti G, Maggiore G, Plebani A, Notarangelo LD, Badolato R: Clinical heterogeneity and diagnostic delay of autoimmune polyendocrinopathy-candidiasis-ectodermal dystrophy syndrome. Clin Immunol 2011, 139(1):6-11.

30. Capalbo D, Giardino G, De Martino L, Palamaro L, Romano R, Gallo V, Cirillo E, Salerno M, Pignata C: Genetic basis of altered central tolerance and autoimmune diseases: a lesson prom AIRE mutations. Int Rev Immunol 2012, in press.

31. Ming JE, Muenke M: Multiple hits during early embryonic development: digenic diseases and holoprosencephaly. Am J Hum Genet 2002, 71:1017-32.

doi:10.1186/1824-7288-38-48

Cite this article as: Capalbo et al: Clinical Heterogeneity in two patients with Noonan-like Syndrome associated with the same SHOC2 mutation. Italian Journal of Pediatrics 2012 38:48.

\section{Submit your next manuscript to BioMed Central and take full advantage of:}

- Convenient online submission

- Thorough peer review

- No space constraints or color figure charges

- Immediate publication on acceptance

- Inclusion in PubMed, CAS, Scopus and Google Scholar

- Research which is freely available for redistribution

Submit your manuscript at www.biomedcentral.com/submit
Ciomed Central 